\title{
Efficacy of Jatropha Sap (Jatropha curcas L.) Cream on Epithelialization Phase of Cutaneous Wound Healing in Mice Using Masson Trichome Staining
}

\author{
M. Nur Salim ${ }^{1 *}$, Ummu Balqis ${ }^{1}$, Rahma Erlis ${ }^{2}$, Dian Masyitha ${ }^{3}$, Erdiansyah Rahmi ${ }^{3}$, \\ Abdul Harris ${ }^{4}$ \\ ${ }^{1}$ Laboratory of Pathology, Faculty of Veterinary Medicine, Universitas Syiah Kuala, Banda Aceh, Indonesia \\ ${ }^{2}$ Study Program of Veterinary Education, Faculty of Veterinary Medicine, Universitas Syiah Kuala, Banda Aceh, \\ Indonesia \\ ${ }^{3}$ Laboratory of Histology, Faculty of Veterinary Medicine, Universitas Syiah Kuala, Banda Aceh, Indonesia \\ ${ }^{4}$ Laboratory of Pharmacology, Faculty of Veterinary Medicine, Universitas Syiah Kuala, Banda Aceh, Indonesia. \\ *Corresponding author. Email: mnursalim@unsyiah.ac.id
}

\begin{abstract}
This study aims to determine the efficacy of $10 \%$ Jatropha curcas Linn. cream on the epithelialization phase of cutaneous wound healing in mice (Mus musculus) using Masson Trichrome staining. This study used nine male mice, aged 2-3 months old with $2 \mathrm{~cm}$ incision was made on the back. The mice were divided into three treatment groups with three replications. Treatment I was applied with cream base (P1), treatment II was applied with 10\% Jatropha's sap cream (P2), and treatment III was applied with sulfadiazine (P3). The wound was treated twice a day for seven days. The observed parameters were collagen density, fibroblast formation and angiogenesis in each treatment group. The data were analyzed by ANOVA followed by Duncan test if there were differences between the treatment groups. The results showed that collagen density in P1, P2, and P3 were $1.58 \pm 0.00,2.04 \pm 0.14$, and $1.95 \pm 0.14$, respectively, indicating a very significant difference $(p<0.01)$. Fibroblasts formation did not differ $(p>0.05)$ among treatments with the values in $\mathrm{P} 1, \mathrm{P} 2$, and $\mathrm{P} 3$ were $2.04 \pm 0.14,1.56 \pm 0.32,1.95 \pm 0.14$, respectively. Angiogenesis in $\mathrm{P} 1, \mathrm{P} 2$, and P3 were $1.46 \pm 0.21,1.87 \pm 0.00,1.46 \pm 0.21$, respectively, which had a significant effect $(\mathrm{p}<0.05)$. It is concluded that application of $10 \%$ Jatropha cream for seven days is effective in increasing collagen density and angiogenesis that accelerate the cutaneous wound healing in mice.
\end{abstract}

Keywords: Jatropha's sap cream, cutaneous wound, angiogenesis, collagen density

\section{INTRODUCTION}

A wound is a damage of the tissue units or components, which causes specific parts of the tissue to be damaged or missing. When injury occurs, several effects will arise, including the loss of all or part of organ function, sympathetic stress response, bleeding, coagulation, bacterial contamination, and cell death [1]. An incisional wound is a clean-cut wound made using a sharp instrument includes all wounds caused by objects such as knives, swords, razors, glasses and sharp axes [2].

The wound healing process is a complex cellular process that focuses on restoring the integrity of the damaged tissue structure and function through three phases, namely inflammatory, proliferation, and maturation or remodeling phase [3]. Within a few hours after the injury, epithelialization occurs where the epidermal which includes most of the keratin begins to migrate and begins to stratify and differentiate to reconstruct the function of the epidermal barrier [4]

Epithelialization is the transfer of epithelial cells from the area around the hair follicle to the wound area. Epithelialization also increases the production of extracellular matrices, growth factors, cytokines, and angiogenesis by releasing growth factors such as keratinocyte growth factor (KGF) [5]. At the time of injury, fibroblasts will migrate to the wound area from the surrounding tissue, then start to synthesize collagen. Fibroblasts will synthesize a temporary matrix consisting of type-III collagen, 
glycosaminoglycans and fibronectin1 which will provide a place for keratinocyte migration [4]. The fibroblasts will then synthesize and secrete KGF-1, KGF-2 (mostly important in humans) and IL-6 which stimulate keratinocytes to migrate to the wound area. Keratinocytes will multiply and differentiate in the epidermis and finally epithelialization occurs, which is marked by replication and migration of epithelial cells in the wound edge [6].

One of the natural ingredients used as traditional medicine is Jatropha Jatropha's sap contains flavonoids, jatrofin, saponins and tannins. Jatropha sap which is angiogenetic has medicinal properties to stop bleeding caused by wounds and has antimicrobial activity that prevents wounds from bacterial contamination [7]. The flavonoids and saponins in Jatropha's sap stimulate new epithelial cells and support the epithelialization process [8]. Saponins can stimulate collagen growth in the healing process, the formation of new cells, and have pain-relieving effect. Jatrofin (containing alkaloids) and tannins are useful as analgesics and antimicrobials [9].

To the best of our knowledge, no study has been performed to investigate the efficacy of Jatropha curcas Linn. cream on wound healing in mice's skin (Mus musculus). Therefore, this study aims to determine the efficacy of Jatropha curcas Linn. cream in the epithelialization phase of wound healing of mice's skin (Mus musculus) with Masson Trichrome staining. The benefit of this research is to obtain adequate information on the efficacy of wound healing of the skin of mice by giving Jatropha cream to the skin of mice seen microscopically.

\section{MATERIALS AND METHODS}

Jatropha sap is obtained from the jatropha plant around the Syiah Kuala University campus, Banda Aceh. The sap is taken by breaking the jatropha plant's leaves, then collected using a small, sterile tube with a rubber cover. Jatropha's sap cream is made on an oil-inwater basis using the ingredients of stearic acid, Cera alba, Vaseline album, Triethanolamine (TEA), Propylene glycol, Aquadest and Nipagin.

Jatropha's sap cream was prepared at Laboratory of Basic Pharmacy, Faculty of Mathematics and Natural Sciences. Maintenance of mice and skin tissue sampling was carried out in animal cages. The process of dehydration, embedding and sectioning of tissues was prepared in the Histology Laboratory. Masson Trichrome staining was performed at Integrated Research Laboratory of Faculty of Veterinary Medicine, Universitas Syiah Kuala, Banda Aceh.

This study used nine male mice (Mus musculus) aged 2-3 months which were placed in individual cages and then adapted for one week. The mice were allotted in three treatment groups, with three mice per group. The back area of the mice was slashed $\pm 4 \mathrm{~cm}$ and anesthetized with local anesthetic (Emla $\AA)$. The $2 \mathrm{~cm}$ incision wound was then made on the back of mice prior to treatment. The mice in treatment I was applied with cream base as a control (P1), while the mice in treatment II and III were applied $10 \%$ jatropha's sap cream (P2) and sulfadiazine (P3), respectively. Each sample group was treated twice a day in the morning (08.00 WIB) and evening (18.00 WIB).

Skin tissue sampling was carried out after 7 days, the mice were euthanized with ether solution. The injured skin was sectioned, then fixed with $10 \%$ NBF solution for 24 hours [10]. Dehydration was performed using graded alcohol $(70 \%, 80 \%, 90 \%$, and 95\%) and absolute alcohol (I, II) for 2 hours, respectively. The sample were cleared in xylol, infiltrated in paraffin, embedded in paraffin block, sectioned using microtome at $5 \mu \mathrm{m}$ thickness, placed in the object glass, and left to stand for 24 hours. The tissues were then stained using Masson Trichrome staining procedure with Goldner's modification. After the completion of staining procedure, the samples were dehydrated with absolute alcohol I, II, and III and xylol III for 3 minutes, followed by clearing and mounting.

The level of collagen density in wound area calculated using the scoring method according Rizka et al. [11] as follows: score 0; no collagen fibers found in the wound area, score 1 ; density of collagen fibers was less than $10 \%$ per field of view (low), score 2; density of collagen fibers was 10 to $50 \%$ per field of view (moderate), score 3; density of collagen fibers was 50 to $90 \%$ per field of view (high), and score 4 :density of collagen fibers was 90 to $100 \%$ per field of view (very high).

Total angiogenesis was scored based on Napanggala et al. [8]: score $1=$ no new blood vessels/visual field; score $2=1-2$ new blood vessels/visual field; score $3=$ more than 2 new blood vessels / field of view). The scoring for fibroblasts formation followed Febram [10]: score $0=$ dead animals; score $1=$ fibroblasts few, sparse or not compact and unevenly distributed; score 2 = fibroblasts are few but have gathered in several places; score $3=$ fibroblasts are compact and solid; score $4=$ fibroblasts solid and compact and the wound is completely closed. The observed collagen, fibroblast, and angiogenesis scoring were analyzed using analysis of variance (ANOVA) continued Duncan's multiple range test.

\section{RESULTS AND DISCUSSION}

\subsection{Collagen Density}

Collagen density on day 7 was observed histopathologically using Masson Trichrome staining 
(green) which is known as special collagen stain. The control group (P1) showed that the wound was still wide, and the collagen was not evenly distributed around the wound. The group giving $10 \%$ Jatropha's sap cream (P2) showed that the wound was small and the collagen was very tight and evenly distributed in the area around the wound. Meanwhile, the sulfadiazine (P3) group showed wide wounds but smaller than the P1 group and the collagen was evenly distributed and not dense (Figure 1).

Statistical analysis using ANOVA showed that the collagen density in P2 and P3 groups were significantly higher $(\mathrm{P}<0.01)$ than $\mathrm{P} 1$ group (Table 1$)$.
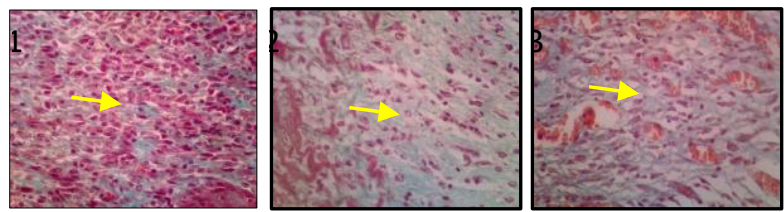

Figure 1 Collagen density photomicrographs (arrow) of wound healing in mice on day 7 (Masson Trichrome, 400x).

$\mathrm{P} 1=$ cream base group

$\mathrm{P} 2=10 \%$ jatropha's sap cream group

$\mathrm{P} 2=$ sulfadiazine group $(\mathrm{P} 3)(400 \mathrm{x})$.

Table 1. Mean collagen scoring on the 7 th day after treatment

\begin{tabular}{|l|l|} 
Treatment groups & Mean of collagen scoring
\end{tabular}

\begin{tabular}{|l|l|}
\hline P1 & $1.58 \pm 0.00^{\mathrm{a}}$ \\
\hline P2 & $2.04 \pm 0.14^{\mathrm{b}}$ \\
\hline P3 & $1.95 \pm 0.14^{\mathrm{b}}$ \\
\hline
\end{tabular}

${ }^{\mathrm{a}, \mathrm{b}}$ Different superscript in the same column indicate a very significant difference $(\mathrm{P}<0.01)$

The content of Jatropha's sap that plays a role in collagen formation is saponins, which play a role in stimulating collagen growth in the healing process according to [9]. Collagen comes from the proliferation of fibroblasts, then the granulation tissue will progressively collect connective tissue (new tissue formation). The saponin content in Jatropha's sap is able to help accelerate the wound healing process [8].

The flavonoids and saponins contained in the Jatropha's sap stimulate the formation of new epithelial cells and support the epithelialization process so that reduction in wound size has a positive correlation with the re-epithelialization process. The faster the re-epithelialization process, the smaller the wound size will be, thus shortening the wound healing process [3].

\subsection{Formation of Fibroblasts}

Histopathologically, fibroblast formation was observed in differences image form. Fibroblasts were denser in P1 compared to P2 and P3. The fibroblast in $\mathrm{P} 2$ was not too dense because it has been replaced by collagen, while in $\mathrm{P} 3$, the amount of fibroblasts and collagen almost the same (Figure 2).

Based on the results of statistical tests using ANOVA in the cream-based group (P1), 10\% Jatropha's sap cream (P2) and sulfadiazine (P3), there was no significant difference $(\mathrm{P}>0.05)$ to the formation of fibroblasts (Table 2).
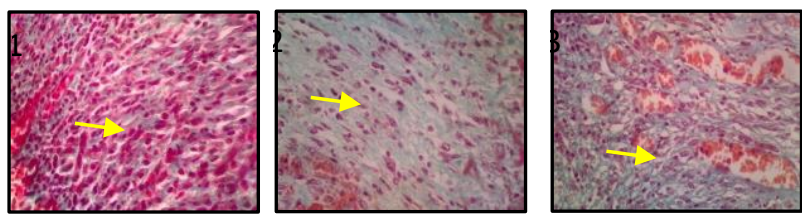

Figure 2 Fibroblasts formation photomicrographs (arrow) of wound healing in mice on day 7 (Masson Trichrome, 400x).

$\mathrm{P} 1=$ cream base group

$\mathrm{P} 2=10 \%$ jatropha's sap cream group

$\mathrm{P} 2=$ sulfadiazine group $(\mathrm{P} 3)(400 \mathrm{x})$.

Table 2. Mean of fibroblast scoring on the 7 th day after treatment

\begin{tabular}{|l|l|}
\hline Treatment group & $\begin{array}{l}\text { Mean of fibroblasts } \\
\text { scoring }\end{array}$ \\
\hline P1 & $2.04 \pm 0.14^{\mathrm{a}}$ \\
\hline P2 & $1.56 \pm 0.32^{\mathrm{a}}$ \\
\hline P3 & $1.95 \pm 0.14^{\mathrm{a}}$ \\
\hline
\end{tabular}

${ }^{\mathrm{a}, \mathrm{b}}$ Different superscript in the same column indicate a significant difference $(\mathrm{P}<0.05)$

The activity of flavonoids in the wound healing process could be observed in increasing the number of fibroblasts [12]. Saponins in Jatropha's sap work to stimulate the formation of new cells or called growth factors. This causes the multiplication and growth of vascular endothelial cells, vascular smooth muscle cells and fibroblasts, resulting in cellular growth which ultimately repairs damaged blood vessel walls [9].

\subsection{Angiogenesis}

Angiogenesis (formation of new blood vessels) in the healing of mice skin incisions observed in P1, P2, and P3 is showed in Figure 3.

Based on the ANOVA test, the cream-based group (P1), 10\% Jatropha cream (P2) and sulfadiazine (P3) had a significant effect on angiogenesis $(\mathrm{P}<0.05)$. Duncan test showed that the $10 \%$ Jatropha's sap cream (P3) group showed significant differences $(\mathrm{P}<0.05)$ compared to the cream-based group (P1) and the sulfadiazine group (P2) on angiogenesis (formation of new blood vessels) (Table 3 ).

The saponin content in Jatropha's sap plays a role in stimulating the growth of new cells. Angiogenesis is a process of forming neovascularization in wounds. 
The presence of neovascular invasion in the tissue will provide adequate oxygen and nutrient needs for the healing process [9].

Priyandari [13] reported that regarding Jatropha sap that is applied topically, the healing process occurs the fastest on the 7th day where the excision wound on mice applied with Jatropha's sap increases wound closure faster.
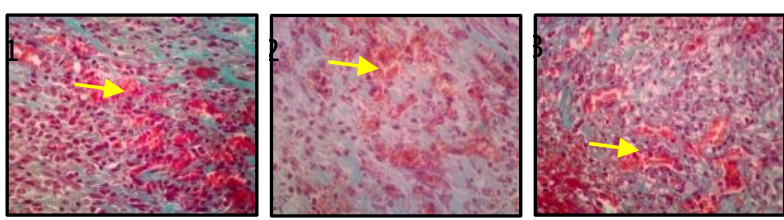

Figure 3 Angiogenesis photomicrographs (arrow) of wound healing in mice on day 7 (Masson Trichrome, 400x).

$\mathrm{P} 1=$ cream base group

$\mathrm{P} 2=10 \%$ jatropha's sap cream group

$\mathrm{P} 2=$ sulfadiazine group $(\mathrm{P} 3)(400 \mathrm{x})$.

Table 3. Mean of angiogenesis scoring on the 7th day after treatment

\begin{tabular}{|l|l|}
\hline Treatment group & $\begin{array}{l}\text { Mean of angiogenesis } \\
\text { scoring }\end{array}$ \\
\hline P1 & $1,46 \pm 0,21^{\mathrm{a}}$ \\
\hline P2 & $1,87 \pm 0,00^{\mathrm{b}}$ \\
\hline P3 & $1,46 \pm 0,21^{\mathrm{a}}$ \\
\hline
\end{tabular}

Note: Different superscript letters in the same column indicate significant differences $(\mathrm{P}<0.05)$

The Jatropha's sap contains flavonoids that play a role not only inhibit the bacterial growth but also inhibits the formation of prostaglandins and stimulates blood cells to accelerate the granulation of tissues in the body [14]. Saponins can increase the optimal supply of oxygen and nutrients and increase the new blood vessel formation needed in wound healing components (angiogenesis) [7].

Collagen normally connects the tissue, traversing the wound with various mediator cells. A collagen matrix, capillarization and cells begin to fill the wound area with new collagen forming scars. This tissue grows from the edge of the wound to the wound bed. The tissue granulation is filled with new capillarization which gives it a luxurious and uneven color. Fibroblasts and macrophages will surround the wound [15]. Macrophages continue to treat wounds by stimulating fibroblasts and the process of angiogenesis. Tissue granulation begins to form, and the epithelialization process begins. Wound contraction is the mechanism by which the edges of the wound are joined as a result of the force in the wound which is steered by myofibroblasts that will bridge across the wound and pull the wound edge to close [16].

\section{CONCLUSION}

Application of $10 \%$ jatropha cream for seven days is effective in increasing collagen density and angiogenesis that accelerate the cutaneous wound healing in mice.

\section{AUTHORS' CONTRIBUTIONS}

MNS and UB designed the research; RE and AH carried out the research; DM and ER performed Masson Trichrome stain; MNS, UB, and RE prepared the manuscript. All authors read and approved the final manuscript.

\section{ACKNOWLEDGMENTS}

The authors gratefully acknowledge the Directorate of Research and Community Service, the Directorate General of Strengthening Research and Development, Ministry of Research, Technology and Higher Education Republic Indonesia for funding this research work.

\section{REFERENCES}

[1] A. Umar, D. Krihariyani, D.T. Mutiarawati, Effect of giving binahong leaf extract (Andrederacordifolia (TEN) steenis) against infectiuos wound healing Staphylococcus aureus on mice, Health Sci. Anal. J. 1(2), (2012) pp. 6875.

[2] R. Puspitasari, Sunyoto, M. Arrosyid, Effectiveness test of aloe vera extract (Aloe vera $L$.) against incisi wound healing on mice, Cerata $\mathbf{J}$. Pharm. Sci. 3(1) (2016) 1-7.

[3] M.N. Salim, M. Silvia, M., D. Aliza, D. Masyitha, C.D. Iskandar, R Rusli, S. Sugito, M. Hasan, M. Sabri, A. Harris, Efficacy of Jatropha curcas latex cream in the epithelialization phase of wound healing in mice skin, E3S Web Conf. (2020) 151, 01038:153-158

[4] T.O.H. Prasetyono, General concept of wound healing, revisited, Med. J. Indones. 18(3) (2009) 208-216.

[5] T. Velnar, T. Bailey, V. Smrkolj, The wound healing process: an overview of cellular and molecular mechanisms, J. Int. Med. Res. 37 (2009) 1528-1542.

[6] S. Guo, L.A. Di Pietro, Factor affecting wound healing, J. Den. Res. 89(3) (2010) 219-229.

[7] U. Balqis, D. Darmawi, C.D. Iskandar, M.N. Salim, Angiogenesis activity of Jatropha curcas 
Linn. latex in cream formulation on wound healing in mice, Vet. World 11(7) (2018) 939-943.

[8] A. Napanggala, Susianti, E. Apriliana, The effect of tropical Jatropha curcas L. plant sap on the healing rate of incisi wounds in Sprague Dawley male white rats, J. Ked. 3 (2014) 5-10.

[9] O.O. Igbinosa, E.O. Igbinosa, O.A. Aiyegoro, Antimicrobial activity and phytochemical screening of steam bark extracts from Jatropha curcas (Linn), Afr. J. Pharm. Pharmacol. 3(2) (2009) 058-062.

[10] B. Febram, I. Wientarsih, B. Pontjo, The Activity of ambon banana tree trunk extract ointment (Musa paradisiaca var sapientum) in the process of wound healing in mice, Tradit. Med. Mag. 15(3) (2010) 121.

[11] A. Rizka, V.S. Budipramana, D. Fauziah, Collagen type 1 density in surgical wounds of wistar rats experiencing anemia due to acute bleeding, Media J. Emerg. 1(2) (2013).
[12] S. Sumartiningsih, Effect of giving Binahong (Anradera Cordifolia) on inflammatory cells and fibroblast cells in hematoma femoris ventralis Rattus Norvegicus, male wistar strain, Airlangga University Postgraduate Program. Surabaya, 2009.

[13] Y. Priyandari, S.A.T.M. Umatjina, Topical giving of Jatropha curcas accelerates the healing time of excision wounds of mice skin, J. Ners Comm., 6(2) (2015) 198-206.

[14] C. Agyare, Y.D. Boakye, E.O. Bekoe, A. Hensel, S.O. Dapaah, T. Appiah T, Review: African medicinal plants with wound healing properties, J. Ethnopharmacol. 177 (2016) 85-100.

[15] T.A. Wynn, L. Barron, Macrophages: master regulator of inflammation and fibrosis, Semin. Liver Dis. 30(3) (2010) 245-257.

[16] T.A. Wynn, L. Barron, R.W. Thompson, S.K. Madala, M.S. Wilson, A.W. Cheever, T. Ramalingam, Quantitative assessment of macrophage functions in repair and fibrosis, Curr. Protoc. Immunol. 93 (2011) 14.22.1-14.22.12. 